\title{
25 Research Square \\ Surgical repair could be best bet for baseball players with posterior labral tear
}

James S. Kercher

Robert P. Runner

Timothy P. McCarthy

Xavier A. Duralde

\section{Video Abstract}

Keywords: Peachtree Orthopedics, Emory University, American Journal of Sports Medicine, shoulder, arthroscopy, posterior labral repair, baseball, throwers labral tear, pitcher, American Shoulder and Elbow Surgeons (ASES), glenoid labrum, batter's shoulder, sublaxation, range of motion (ROM), return to play, posterior instability, postoperative outcome, patient satisfaction, pain

Posted Date: September 20th, 2019

DOI: https://doi.org/10.21203/rs.2.14987/v1

License: (c) (1) This work is licensed under a Creative Commons Attribution 4.0 International License. Read Full License 


\section{Abstract}

A recent study suggests that baseball players with a torn posterior labrum, the back rim on the socket that keeps the shoulder's ball joint in place, could benefit significantly from arthroscopic surgery. Among 32 young athletes with this injury, more than $90 \%$ returned to play, with $61 \%$ returning to their previous performance level. Labral tears are common among contact and non-contact athletes alike, with different types of stresses leading to different types of tears. Among football linemen and baseball pitchers, tearing of the posterior labrum is common. Unfortunately, there's a big disparity in the amount of research dedicated to each type of athlete. While linemen have proven able to return to sport following labral repair, the small amount of available research on baseball players suggests that pitchers won't necessarily enjoy the same result. To bridge that gap, researchers looked at 32 male baseball players who underwent posterior labral repair after a failed course of non-surgical rehabilitation. Three main types of tears were observed, with throwing as the dominant cause of injury. Among the patients, $94 \%$ were able to return to the field after arthroscopic surgery, with $61 \%$ returning to their previous level of play; pitchers showed a lower return to form than did position players, and $6 \%$ of patients did not return to sport. In addition, patient-reported shoulder instability improved by more than 30 points on average following surgery, and average pain scores decreased significantly. Though encouraging, the findings should be interpreted with caution. Players were examined retrospectively, indicating both limited control over test conditions and the lack of a control group. Additionally, athletes were treated by a high-volume shoulder specialist. So the results may not translate to all baseball players undergoing surgical repair. Despite those limitations, the study's findings could still prove valuable, providing some measure of guidance to injured baseball players seeking to recapture their previous level of performance. 